\title{
Goce visual. Mujeres en el firmamento según las notas de Horacio Quiroga
}

\author{
Prazer visual. Mulheres no céu de acordo com as notas de Horacio \\ Quiroga
}

Women in the film world according to the notes of Horacio Quiroga

\section{Laura Lorena Utrera ${ }^{1}$}

\begin{abstract}
Resumen
Este artículo tiene como objetivo analizar la influencia de la estrella de cine en la conformación de modelos socioculturales para la vida moderna. Mostraremos cómo, en 1918, el escritor Horacio Quiroga publica notas en las que reflexiona sobre la belleza de las mujeres del cine (objeto de deseo) y su actuación (técnica propia del nuevo arte); sobre el Star System y la Star como mercancía; sobre el enamoramiento e identificación de los fans con su estrella favorita y sobre los procesos inconscientes de naturaleza discursiva que se generan en la creencia de lo que muestran las revistas de cine sobre la vida de las estrellas. A estas primeras intuiciones de Quiroga las articularemos críticamente con las consideraciones teóricas de Walter Benjamin, Edgar Morin, Siegfried Kracauer, Corneluis Castoriadis y Laura Mulvey.
\end{abstract}

Palabras claves: Mujeres Modelización Mercancía Identificación Modernidad.

\section{Resumo}

Este artigo tem como objetivo analisar a influência da estrela de cinema na modelagem de modelos socioculturais para a vida moderna. Mostraremos como, em 1918, o escritor Horacio Quiroga publica notas nas quais reflete sobre a beleza das mulheres do cinema (Objeto de desejo) e sua performance (técnica típica da nova arte); sobre o Star System e a Star como mercadoria; sobre a paixão e identificação dos fãs com sua estrela favorita e sobre os processos inconscientes de natureza discursiva que são gerados na crença do que as revistas de cinema mostram sobre a vida das estrelas. Essas primeiras intuições de Quiroga as articulam criticamente com as considerações teóricas de Walter Benjamin, Edgar Morin, Siegfried Kracauer, Corneluis Castoriadis y Laura Mulvey.

Palavras-chave: Mulheres, modelando, Identificação, Mercadorias, Modernidade.

\begin{abstract}
The goal of this article is to analyse the influence of the movie star in the composition of sociocultural models for modern life. We will show how, in 1918, writer Horacio Quiroga published notes in which he reflected on the beauty of women in film (desire object) on their performance (particular technique of the new art); on the Star System and the Star as a commodity; on the infatuation and identification of fans with their favourite star and on
\end{abstract}

\footnotetext{
${ }^{1}$ Doctora en Humanidades y Artes com mención en Literatura; Universidad Nacional de Rosario y CONICET; Rosario, Santa Fe, Argentina; laura.utrera2014@gmail.com.
} 
the subconscious processes of discursive nature that generate from the belief of what film magazines show about the star's lives. We will critically articulate Quiroga's first intuitions with the theoretical considerations of Walter Benjamin, Edgar Morin, Siegfried Kracauer, Corneluis Castoriadis and Laura Mulvey.

Keywords: Women; modelization; commodity; identification; modern age.

“(..) yo conozco a cualquier estrella de cine tanto, o más aun, como a mi propia mujer"

(...) cada quien se construye una Greta Garbo para su uso personal, enteramente diferente de la de los demás, pero enteramente verdadera para cada quien" (Arraíz, 2005, p. 211)

"Bárbara, Bar... ba...ra, Aspiro tu nombre en la sala sucia" (Olivari, 2000, p. 27)

\section{Introducción. El firmamento, ayer y hoy}

"Un fanático se hizo 82 tatuajes con la cara de Julia Roberts". Este es el titular de una noticia periodística publicada en Infoshow el 15 marzo de 2011 que muestra fotografías de un vendedor de diarios de Chile llamado Miljenko Parserisas Bukovic exhibiendo los dibujos de la diva tatuados en sus brazos y en su torso, desnudos.

"Me hice el primer tatuaje en el brazo", comentó el fanático, que vuelve a ver una y otra vez la película Erin Brockovich (Steven Soderbergh, 2000) en búsqueda de un nuevo gesto de la Roberts para ir a lo de su tatuador, Leonardo Alarcón, autor de sesenta de los dibujos de su cuerpo. Alarcón, especialista en retratos, cuenta que le cobra sólo unos 10 mil pesos por cada tatuaje sobre los 15 y 70 mil que habitualmente percibe por trabajos similares. Alarcón confiesa que mientras tatúa al fanático: "vemos su película favorita, Erin Brockovich". El sueño de Bukovic es cubrir su pecho y espalda con más imágenes de la actriz extraídas, ahora, de la película Mujer Bonita (Garry Marshall, 1990). ${ }^{2}$

La noticia puede resultar una reconstrucción grotesca de un personaje entrañable de algún barrio de Chile -que además es el diariero- o una curiosidad desopilante y habitual de un viejo alienado que dedica horas de trabajo - cada tatuaje representa en sí mismo un valor económicoy milímetros de su cuerpo al registro y devoción auténticos por las facciones del rostro de Julia Roberts. Con todo, y como parte del público consumidor, Bukovic es una muestra de que toda

2 En: https://www.infobae.com/2011/03/15/569710-un-fanatico-se-hizo-82-tatuajes-la-cara-juliaroberts/ 
estrella es creada por el deseo de estar en presencia de adorados cuerpos y de rostros singulares.

Con la técnica del tatuaje el fanático rinde tributo a Julia Roberts pero también la lleva inscrita en su piel, se la apropia de la manera más erótica, más económica: porque paga por cada imagen tatuada y porque no necesita más espacio que el que ocupa (en) su cuerpo para (re)tenerla. El tatuaje resulta ser una técnica que copia y repone imágenes de un mismo rostro y que funciona a la manera de recurso técnico casi como un primer plano y/o close up, recursos, ambos, que convierten los detalles cotidianos en objetos sorprendentes (Balázs, 1999, p. 308). En el caso de un rostro bello como el de Julia Roberts, la técnica del tatuaje restituye las facciones y vuelve cercano (cotidiano) un objeto sorprendente. Pero también, el caso del tatuaje no hace más que evidenciar el instinto escopofílico de mostrar a la mujer como materia prima (pasiva) para la mirada del hombre (activo), según Laura Mulvey (2001, p. 370).

En este marco, resultan significativas las categorizaciones que al respecto atribuyó Béla Balázs al close up del cine americano. Precisamente porque el acto de leer o escuchar la cara de un actor lo mitifica de una manera parecida al proceso de génesis de creación de los dioses, tornando a ese rostro como Universal. Este recurso técnico representa el instrumento creativo de un gran antropomorfismo visual que creemos se desenvuelve de modo similar en los tatuajes grabados en el cuerpo del diariero. El valor cultual de las imágenes de las divas no hace más que rememorar el culto aprehendido de la religiosidad con la distancia que impone lo bello porque esas imágenes eran incluso perturbadoras. ${ }^{3}$

Sin mayores reparos -más allá de la técnica del tatuaje, del tono de la escritura y de los años transcurridos-, esta noticia puede articularse con las reseñas que en los años treinta publicó al respecto Roberto Arlt: “¿Soy fotogénico?”, “Me parezco a Greta Garbo”, "Parecidos con artistas de cine" o "Recordando el Eclesiastés". Todas ellas publicadas por primera vez en el diario El Mundo y en las que lo que subyace es el concepto de apariencia. ${ }^{4}$

Siguiendo este tono, puede agregarse a dicho corpus las secciones “¡Pregunte Ud.!” o "Lillian Gish dice..." de revistas como Cine Mundial, secciones que, por cierto, no faltan en ninguna de las revistas de cine de los años veinte, empeñadas, todas, por responder a las preguntas de los espectadores. Como así también, esos apartados de las revistas que promueven concursos con la premisa “¿soy o no fotogénico?” y a la que los aspirantes envían fotos en las que exponen

\footnotetext{
${ }^{3} \mathrm{Al}$ respecto, se sugiere ver: Georges Bataille. El erotismo. Buenos Aires: Tusquets Editores, 2000. Respecto del concepto de close up, se sugiere ver: Béla Bálazs. "The face of man". En Film theory and Criticism: introductory readings. New York: Oxford University Press, 1999, pp. 306-311.

${ }^{4}$ Las notas de Arlt se encuentran reunida en Roberto Arlt. Notas sobre el cinematógrafo. Ver Bibliografía.
} 
sus retratos en traje de baño con la melena revuelta, "la cara empolvadita, la mirada melancólica" (1997, p.41) o los que desempeñan una tragedia con su melenita revolucionada, "los ojos saltones que parecen huevos pasados por agua y un puñal de cartón en la mano" (1997, p.41).

Este tono formula y reformula un fenómeno que sigue funcionando luego de ochenta años: photogenie (fotogenia), el sine qua non inefable de la expresión cinematográfica. El concepto con el que Louis Delluc define el cine de los años veinte y que, por cierto, no debe desprenderse de la conexión entre el director o cineasta y el mundo, más aún, entre el cineasta y el público masivo porque, precisamente, y a causa del efecto producido por la proximidad que logra la cámara, se contribuye al carácter semiótico subjetivo del cine, “yo he visto la cara a diez o cinco centímetros de la mía; es decir, tan próxima como la de la persona más querida que me da un beso" (Arríaz, 2005, p. 212).

\section{Las Stars de Quiroga}

Del corpus de las notas de Horacio Quiroga sobre cine, las dedicadas a las estrellas de Hollywood, pueden ser leídas, como un tópico menor. Incluso la primera nota publicada en 1918 en la revista El Hogar lleva por título el nombre de un actor: Jorge Walsh. Sin embargo, no lo son. Porque, precisamente, en esta zona subsidiaria, el narrador despliega una lectura ocurrente y chispeante, al pronunciar y detectar ciertos formatos que estereotipan conductas sociales (lo público) y al mostrar la modelación que consigue el poder de cercanía de las imágenes (lo privado). ${ }^{5}$

Hollywood comprendió, tempranamente, que para fabricar estrellas debía manufacturar sus vidas privadas como parte de una máscara pública. Más allá del ímpetu personal de estas celebridades por proteger su privacidad, la exposición a la que su profesión las somete, vuelve casi imperceptible la línea de límite que se traza entre lo privado y lo público. Quiroga, al ritmo de Hollywood, alcanzó a vislumbrar el trabajo de esta maquinaria. 6 “Aunque la película [...]

\footnotetext{
${ }^{5}$ Las notas sobre cine se encuentran reunidas en Horacio Quiroga, Arte y lenguaje del cine (1997), ver bibliografía. En cuanto a la edición de cuentos, se utilizará la edición: Horacio Quiroga. Todos los cuentos (1996). Ver bibliografía.

${ }^{6}$ En 1999, se estrena Nothing Hill (Roger Michell), una comedia romántica coproducida por Inglaterra y Estados Unidos y protagonizada por Julia Robert, Hugh Grant, Rhys Ifans, entre otros. Esta película responde de manera diferente a la interpelación sobre la vida de una estrella famosa y a la conquista de "su amor". Será un vendedor de libros poco cinéfilo llamado Williams -interpretado por Grant- quien se enamora de Anna Scott -Julia Robertssin saber que se trata de una celebridad de Hollywood. Esta comedia muestra precisamente el sueño convertido en realidad: el amor entre una celebridad y un hombre vulgar. Más allá de las actuaciones de los protagonistas y del gran hallazgo de la historia que es, precisamente, el personaje llamado Skype -el amigo desarrapado y sucio de 
está ahí para ser vista, las condiciones de proyección y las convenciones narrativas proporcionan al espectador la ilusión de estar mirando un mundo privado" (Mulvey, 2001, p. 369).

Por un lado, el narrador traslada a los cuentos sobre cine cierta renovación temática y sociocultural que viene del nuevo arte y que atañe, estrictamente, a la figura femenina. De hecho, en los cuentos sobre cine formula un rol protagónico para la mujer, ocupado, claro está, por una celebridad. Por otro, en las crónicas evoca y promueve una novedosa experiencia estética a través del uso de estas stars que, si bien prefiguraron la novedad, poseen, asimismo, la consistencia de lo cotidiano devenido del consumo.

Las estrellas son objetos de deseo, populares y masivas; manipulables y que manipulan por vías ajenas porque muchas veces ese poder se lo otorga el mismo público. A su vez, intervienen en la vida de los ciudadanos comunes, se meten en sus casas, en sus vidas y en sus cuerpos; modelan experiencias, así como también, representan ni más ni menos que un nombre propio común a los espectadores. Con ellas, se repone la significación de las imágenes que los fanáticos guardan en sus memorias y que, por supuesto, están vinculadas a un contenido de verdad. La labor de las revistas, a través de la utilización de determinado tono en las notas y de las fotos ilustrativas, evidencia una relación entre ese personaje que los magazines reconstruyen o, sencillamente, inventan y los espectadores que creen en ese personaje: la detenida y minuciosa descripción de sus vidas parece detentar una pulsión de verdad. Para decirlo con Graciela Speranza, las estrellas son estereotipos que modelan la experiencia femenina y definen sus objetos de deseo (2003, p.27).

Siegfried Kracauer, entendía el cine y la fotografía como "superficies" aunque opacas visibles, consumibles y masivas. Ellas representan el síntoma de una cultura urbana, que junto al retumbar y chirriar fabril, constituyen "la percusión del capitalismo" (2008, p. 22). Al tratarse de puras superficies, de lo ancho y de lo alto, puro espacio que ocupan en la pantalla, las mujeres del cine asumen una exacta y pormenorizada noción de su cuerpo, de su vida y, en consecuencia, se presentan a disposición del espectador que puede colocar, en su dimensión sin profundidad, lo que se le ocurra: intenciones, deseos, placer, presunciones, pensamientos, sensaciones y

William - la historia muestra una posibilidad que se articula con lo que la actriz sostiene en una entrevista realizada luego del estreno de la película: "Una actriz y un tipo normal pueden ser felices juntos. Cualesquiera sean las circunstancias, si dos personas se quieren, no importa quiénes sean o dónde vivan. No hay barreras si dos personas se aman" (publicado en http://www.decine21.com/Peliculas/Notting-Hill-5221). Más allá de la sospecha que a todos nos asalta, la de si esto lo dijo o no la Robert, lo que tampoco resulta relevante para el caso, lo cierto es que en ese entramado titulado "Julia Robert opina de su otro yo" se pone en juego la naturaleza estelar de la vida de una actriz de Hollywood. 
discursos. De estas estrellas, de estas mujeres se tiene un conocimiento geométrico: en ello está su belleza y su precisión (Arráiz, 2005, p.210).

En las notas sobre cine, Quiroga (re)construye las vidas privadas de las estrellas. Lo hace, creyendo y haciendo chismografía a través de la utilización de restos reales o (cuasi) inventados que sustrae de las revistas de chismes de los años veinte. A esta aparente banalidad universal que sólo queda inscripta en una nota que pretende mostrar un fragmento melodramático de la vida de alguna celebridad, donde lo que prevalece gira en torno al amor (líos de alcoba, separaciones, romances atrevidos), a la locura (alcohol, drogas, garden parties) y a la muerte (suicidios, muertes tempranas por enfermedades fatales, accidentes)- la acompaña la información que se pretende real porque, precisamente, esta apariencia que se vuelve evidente en la expresión de lo banal, recompone y restituye la vida de una estrella, de su experiencia artística (o al menos ese será su objetivo de máxima). Dicha idea se proyecta, asimismo, en el sostenimiento de una fuerza inherente de "verdad". Esta potencia borra la mera trivialidad que despoja la nota porque, naturalmente, el carácter banal cambia de estado a partir del derecho adquirido: la estrella tiene derecho a la banalidad porque precisamente dicha condición forma parte de la constitución de su valor de cambio casi como una condición propia, inherente a su idiosincrasia. Y en este sentido, son las mismas revistas las que publican notas de artistas que denuncian la verdad vuelta apariencia. Natacha Rambova, viuda de Valentino, en una nota que publicó la revista de La Nación, dice: "Hollywood, la ciudad malvada, infierno dorado y reino de la farsa y de la apariencia. ¡Nada más que engaño! Hollywood, lucha de nadies para convertirse en "alguienes" y donde todos pretenden ser lo que no son". 7

Quiroga ironiza sobre las vidas al borde de las estrellas, aunque la ironía decrece cuando el narrador cree que, lo que resulta ser el simulacro de la vida compuesto por el mundo del cine, puede ser verdadero, prefigurándose, de este modo, un espacio imaginario que el cine establece y reserva. La potencia de la chismografía tiene petición de "verdad" o, por lo menos, es posible cierta concepción de real en este tipo de comentarios: ${ }^{8}$

A raíz de su reciente divorcio, se ha creado una situación un poco difícil en el estudio de Robert Brunton, en Los Ángeles. Los exesposos [Mary Pickford y Owen Moore] se hallan actualmente trabajando en el mismo conjunto. (...). Y esta perspectiva parece tener excitada a la gente que los rodea (tan apasionada por sus potins de entretelones como nosotros mismos). ¿Se hablarán? ¿Simularán un amor que tal vez sienten aún? (Quiroga, 1997, p. 131).

\footnotetext{
${ }^{7}$ Mom, Arturo S. "Natacha Rombova habla con el espíritu de Valentino" en revista La Nación, número 1, tomo 1, Buenos Aires, 7 de Julio de 1919.

${ }^{8}$ En esta serie, resultan significativas las notas que se inmiscuyen en la vida de las estrellas y que bien podrían haber formado parte de la chismografía que se publicaba, por ejemplo, en las revistas argentinas como Imparcial Film, Cine Revista y Cinema Chat. Algunas de ellas son: "Algunas estrellas", "Mary Pickford - Owen More", "Vivian Martin", "Constante Talmadge", "Kitty Gordon”, "Dorothy Gish y Richard Barthelmess", "Variedades", "Dorothy Dalton", "El beso en el estado de Texas", "Las camelias blancas".
} 
“(...) las gentes del cine gozan de este privilegio de universalidad, y en el suntuoso comedor de una avenida del norte como en la modesta mesa de un barrio extramuros padres, hermanos y niñeras están a la hora presente preguntándose por qué Lew Cody, si ya no ama más a Dorothy Dalton, le envía un ramo de camelias blancas. Y lo que es más informal aún, a nosotros mismos (¡celos de espectador!) nos interesa la cosa" (Quiroga, 1997, p. 143).

"Se aburría bajo las magníficas palmeras de Palm Beach. Por lo cual envió una postal con dicha avenida a su mejor amigo de Nueva York, con esta leyenda de puño y letra: "Gran sitio para caminar; pero nadie con quien hacerlo". Ignoramos si el mejor amigo acudió en consuelo de la solitaria estrella” (Quiroga, 1997, p. 120)

A la vez, quien observa a la estrella cree estar frente a la diva porque su éxito reside, precisamente, en la facultad de concederle al que mira esa propiedad, llevando el cine al campo de la pura reacción multitudinaria. Esta sensación comienza cuando el sujeto se enfrenta a su fotografía, donde cree ver en la foto a la propia estrella mujer. En ello colaboran, por cierto, las portadas de las revistas que nos recuerdan su realidad de carne y hueso y rememoran su belleza. Para decirlo con Kracauer, la fotografía oficia de intermediaria y es un signo óptico de la diva cuyo conocimiento tiene validez (2008, p. 20). Allí comienza el proceso alienante que sufre el espectador.

Quiroga, en estas notas, repone un imaginario cinematográfico que antes de replicar a un espacio meramente reproductivo tiende a una contribución productiva por medio del uso del campo lexical de Hollywood a través del empleo de metáforas estereotipadas. Y es productivo porque Quiroga cuenta con mucho capital acumulado (imágenes, revistas sobre cine, imaginario). Por ejemplo: "cine como fábrica de sueños", “el cine es la concreción de algo que fue soñado", "garden-party", “estrellas fugaces", “el cielo del cine”. Estas constelaciones verbales componen el arsenal afectivo de Quiroga pero también del público.

Su rol de espectador experimental y, por tanto, su posición individual frente a la pantalla-espejo se efectúa en medio de experiencias colectivas similares de proyección-identificacióntransferencia, lográndose en él un reconocimiento de las múltiples experimentaciones de su 'primera persona' -que no entendemos como individual sino como social-y construyéndose una subjetividad en la medida en que, en el imaginario cinematográfico, el espectador lleva a cabo su identificación que incorpora en su yo el ambiente que lo rodea y lo integra afectivamente (Castoriadis, 1998, p. 229). ${ }^{9}$

\footnotetext{
${ }^{9}$ Asimismo, Edgar Morin opina al respecto que "el complejo de proyección-identificación-transferencia domina todos los fenómenos psicológicos llamados subjetivos, es decir, que traicionan o deforman la realidad objetiva de las cosas, o bien que se sitúan deliberadamente fuera de la realidad (entados anímicos, ensueños)” (2001, p. 83). Por su parte, el término garden-party había sido utilizado por Quiroga en 1908 cuando escribió el relato "La vida intensa" (Caras y Caretas, 16-5-1908).
} 
Desde este marco, siguiendo la lectura de Rosalind Coward, podemos advertir que "lo inconsciente se origina en el mismo proceso mediante el cual el individuo penetra en el universo simbólico" (1976, p. 8). Esto plantea dos cuestiones insoslayables: que los procesos inconscientes son de naturaleza discursiva, la primera; y, la segunda, que la vida psíquica es a su vez individual (privada) y colectiva (social). ${ }^{10}$ De modo que, mediante el cine, Quiroga accede a un universo simbólico de proyección-identificación-transferencia, a un espacio múltiple, mixto y democrático -como él mismo lo supo advertir en la nota de 1922, "Los intelectuales y el cine" porque el mundo narrado en estas crónicas pertenece al incipiente imaginario social que se encuentra en formación en los años veinte.

Los admiradores ven en la estrella un modelo a seguir que marca tendencias y que impulsa el deseo mimético planteado tanto por la exhibición pública de los cuerpos cuanto por los productos que los artistas promocionan en las revistas. El formidable sistema publicitario de Hollywood "anticipa o acompaña cambios en la cultura femenina de las capas medias" (Sarlo, 1999, p. 22) y, en consecuencia, logra empañar la visibilidad doctrinaria que, en términos de leyes de convivencia citadina, esgrimía la prensa letrada de esos años.

Las publicidades que invaden las revistas exhiben muñecas, perfumes y cremas que explicitan el valor de uso y de cambio por parte de una diva en particular y provocan, naturalmente, su consumo. Con ello, se activa en los espectadores el proceso de identificación-transferencia pero también y, de un modo simultáneo, de admiración.

Rodolfo Valentino lleva en el cabello Vaseline, motivo por el cual crece notablemente la venta de ese producto en todo el mundo. Los consumidores compran tales manufacturas "porque no pueden resistir el deseo de imitar las estilizaciones corporales de las estrellas que idolatran" (Gumbrecht, 2004, p. 119). Esta conducta no dependerá sólo de las leyes de la oferta y demanda, sino que se consolida en el poder supremo de la estrella sobre la sociedad y de su alcance; en el magnetismo que, en este caso, produjo Valentino sobre la platea. Cuando algunos de los admiradores se enteran de la muerte del actor como consecuencia de una úlcera, no resisten la pérdida y asumen el simulacro: se suicidan, al igual que el puritano protagonista del cuento homónimo de Quiroga. Ya se trate de la mera imitación automatizada -correlato de la persuasión que las estrellas provocan en los espectadores-, o, de formar parte de la esfera secular de su eternidad, lo cierto es que unas pocas semanas después de la muerte de Valentino,

\footnotetext{
${ }^{10}$ Coward, Rosalind, "Lacan and Signification: An Introduction”, Edinburg Magazine, n. 76, 1976, pp. 6-20. Ensayo citado en Nuevos conceptos de teoría del cine (1999), pp. 147-148. Nos interesa esta perspectiva en cuanto a la caracterización de Metapsicología, que trata, específicamente, de la construcción psicoanalítica del sujeto espectador de cine en términos de la circulación del deseo.
} 
y como consecuencia de la canción editada tras su muerte "There's a new star in heaven tonight", los suicidios en cadena de muchas de sus admiradoras puedan deberse al deseo impulsivo de compartir ese cielo estelar con Rudy.

Esto, de algún modo, está refrendado en la insistencia de Quiroga por instalar el paralelismo necesario que se vale de la reposición de la vida de los actores fuera y dentro de los estudios de grabación:

"la vida de un actor fuera de los estudios es tan interesante como su actuación misma en la pantalla" [...] "No hay acaso en todo esto [Quiroga se refiere a las vidas al borde de las estrellas] otro motivo que el fastuoso miraje de juventud, belleza y opulencia atribuidas a las estrellas de Hollywood, miraje que la pantalla, con sus vivas escenas de ternura entre esas mismas estrellas, no consigue sino reforzar" (Quiroga, 1997, p. 221).

La influencia de los modelos instituidos por las figuras del cine se produce, como se advierte, por mediación de procesos imaginarios de identificación del fan con la estrella. Hollywood comprendió perfectamente que haciendo pública la vida privada de una star dispone de un mecanismo eficacísimo de referenciación y traducción del mito en valores y pautas del comportamiento cotidiano (Martín-Barbero, 1987, p. 64) y de ese modo, a su vez, publicita su cine, asegurándose, importantes sumas de dinero y, por tanto, promocionando la mercantilización de la estrella de cine. Los vendedores de ilusiones no pueden cesar de provocar, en el consumidor, necesidades nuevas y cada vez más particulares, porque el valerse de su exigencia es lo que hace al cine el arte más comercial de todos.

La pantalla proporciona una intimidad absoluta: los hombres inmersos en la imperiosa soledad de la sala -en la que la oscuridad facilita el anonimato y la desaparición de convenciones sociales- tienen acceso a ver de cerca una cara bonita, una boca carnosa y un escote sugerente: "Cuando se ha resistido a una cálida boca que implora ser besada, se resiste muy bien a una danzante ilusión de celuloide" (Quiroga, 1996, p. 765). Esta posibilidad es harto significativa, para un hombre de los años veinte, puesto que en ese Buenos Aires las normas de convivencia y relación restringían la contingencia de mirar de frente y en un lugar público a una dama o a un caballero:

"he pasado treinta y un años de mi vida esperando, esperando. ¿Esperando qué? Dios lo sabe. Acaso el bendito país en que las mujeres consideran cosa muy ligera mirar largamente en los ojos de un hombre a quien ven por primera vez (...) no debe olvidarse que contadísimas veces en la vida nos es dado ver tan de cerca a una mujer como en la pantalla. El paso de una hermosa chica a nuestro lado constituye ya una de las pocas cosas por las cuales valga la pena retardar el paso, detenerlo, volver la cabeza -y perderla-" (Quiroga, 1996, p. 437).

Quiroga publicó "El beso" en Caras y Caretas el 3 de abril de 1920. En la nota detalla dos razones que llevan a la utilidad del recurso en el marco de una historia, ambas no carecen, según 
lo advierte, de legalidad: la una, condensa y define una historia de amor, la otra sirve de pararrayos de una pasión que no puede ser contenida. Sin embargo, también le resulta preciso advertir que la inclusión del beso puede estar sugerida a través de las ventajas producidas por la verdad y naturalidad del gesto, de un efecto en la actuación, donde un íntimo abrazo o una lenta caricia de mano o cualquier toma que involucre el gesto amoroso pueden mostrar, acaso con más ternura, el reemplazo del beso. Naturalmente, Quiroga piensa esta tercera opción desprovista de propósitos morales (o desde las buenas costumbres), quiero decir, el narrador no está pensando en la aplicación de la censura a dichas escenas amorosas sino que está hablando de narración en el cine, está escribiendo desde el concepto de efecto. También, Quiroga entiende que el recurso del beso sugerido puede instrumentarse a través del uso del oscurecimiento de la escena, proyectando las siluetas, con el que la "escenita adquiere una fuerza de sugestión por encima de todo elogio". Resultando, con todo, la arremetida contra los preceptos de algunos clubes femeninos que consideran el beso como "acto inadecuado, inmoral y poco limpio". En el comentario que hace de la cinta titulada Generoso conquistador (retitulada en los cines de Buenos Aires como El hombre de los mil amores) el recurso de un beso robado articula la historia, es decir, el cuadro del beso resulta un procedimiento argumental por el que ingresa la angustia a la comedia y por el que se revela el amor; "el recurso del beso domina desde el principio al fin el ambiente de la comedia”, argumenta Quiroga. ${ }^{11}$ Asimismo, "La jangada", bosquejo de guión cinematográfico que escribe en 1917, se cierra con un beso. La escena final de lo que sería una película, al mejor estilo de las narraciones románticas de Hollywood, se justifica con un beso entre Orgaz y Beatriz.

Este tema no estuvo fuera del debate político de esos años y fue José Ingenieros quien incluye, en el texto de divulgación científica La psicopatología en el Arte (1920), un texto que escribió en su juventud: "El delito de besar". Ingenieros trabaja, precisamente, la idea del beso en vinculación con el delito y con ciertas formas de simulación, subrayando la amenaza de su práctica en lugares públicos. O, como la respuesta que tuvo Arlt cuando en 1932 polemiza con Roberto Ghioldi, secretario del Partido Comunista argentino. Arlt sufre insistentemente las críticas de Ghioldi quien, en las filas de la revista Bandera Roja, lo invita a que abandone su actitud "pequeño burguesa", se sume a las filas marxistas y comparta las duras experiencias del

\footnotetext{
11 "Un beso que llevó dos vidas al vértigo, y que, sin embargo, fue robado" en Caras y Caretas no 1125 del 24 de abril de 1920. Asimismo, Pablo Rocca, en la compilación Lo que no puede decirse y otros textos (1994), rescata la nota "El beso: su uso y abuso", publicado inicialmente en Mundo argentino el 24 de noviembre de 1928. Rocca, Ver bibliografía.

En anexo 2 se incluye una foto que grafica cómo las revistas ilustradas reproducían imágenes de actores besándose. Foto tomada de Imparcial film.
} 
proletariado. Ghioldi invitaba a Arlt a que traduzca estos preceptos en su literatura y que diga desde la síntesis de un materialismo aleccionador y pedagogizante. Para Arlt, la relación entre intelectuales y proletariado era cultural y en todas las intervenciones que hace sobre el asunto remarca que tanto el intelectual, el obrero, el político y el militante representan un conjunto de identidades incomunicables. En medio del debate, Arlt lanza la famosa frase: "De cien proletariados... noventa ignoran quién es Carlos Marx pero noventa pueden contestarle en qué estilo daba besos Rodolfo Valentino...".12

Se concibe así un imaginario cinematográfico entendido en tanto espacio de producción y transformación de significaciones políticas y socioculturales; instancia de creación en que una sociedad consume y conoce desde la mirada (que, por supuesto, paga bien poco por una función de cine, por folletines y por revistas ilustradas). Específicamente, será la posición que cada espectador ocupe dentro del colectivo anónimo la que determinará el consumo de los clisés y estereotipos que no anulan cierto plus estético y que son narrados a través de diferentes géneros discursivos: chismes, notas y reseñas, películas y ficciones cinematográficas.

A la vez, lo que sucede con las imágenes de las estrellas en la pantalla es algo muy singular: es un sistema pared blanca-agujero negro, que puede definirse como la máquina abstracta de la rostrificación por la cual se proyectan todos los objetos que queden atrapados en la máquina, vale decir, una casa, partes del cuerpo, un utensilio, un rostro, todo. El poder del cine, advierten Gilles Deleuze y Félix Gauttari, reside en los rostros de las estrellas y en el primer plano, pero en cualquier caso el rostro no actúa como individuo, "la individuación es el resultado de la necesidad de que haya rostro" (Deleuze y Guattari, 2006, p. 181).

Las stars, sin más, representan la lejanía, lo inaccesible, lo imposible, aquello que se vive deseando pero que se impone, por su propio esplendor, como ajeno. Y si las estrellas no representan una cercanía es porque su inaccesibilidad es la cualidad fundamental de la imagen cultual de la obra cinematográfica, vale decir, "la manifestación irrepetible de una lejanía, por cerca que esta pueda estar" (Benjamin, 2009, p. 94) que es, precisamente, el concepto de aura de Walter Benjamin. El culto a las estrellas se encuentra promovido por el capital, que permite la conservación de su encanto de personalidad consistente, como señala Benjamin, a un "encanto corrompido de su carácter de mercancía". Esto lo lleva a pensar en que el aura tendía a reaparecer a través de la construcción de lejanía que promueve la estrella. La reproductibilidad

\footnotetext{
${ }^{12}$ Citado en Sylvia Saítta. El escritor en el bosque de ladrillos. Una biografía de Roberto Arlt, Buenos Aires, Sudamericana, 2000, p. 125.
} 
técnica se funda en la técnica de su reproducción que no sólo posibilita de manera directa la difusión masiva de la obra sino su fuerza (Benjamin, 2009, p.103).

El rol femenino de las estrellas quedará determinado por "arquetipos contradictorios": la vamp destructora y fatal ${ }^{13}$, la joven virgen inocente e ingenua, la mujer bella. A partir de los años treinta se produce una evolución que no sólo afecta a la técnica del cine sino también a la vida privada de la estrella, que se convertirá en cosa corriente y familiar, su figura se profana "sin perder por eso sus cualidades míticas esenciales" (Speranza, 2003, p. 207). Esto se comprueba a través de una renovación discursiva que se observa en las notas de los años treinta, en cómo los lectores y los cronistas comparten cierta complicidad -es como si, continuamente, estas notas se encontraran sobrevoladas por un rumor, por un "esto ya se sabe"-. Las críticas muestran un "conocimiento" dosificado sobre los caracteres propios de una estrella de Hollywood que, por cierto, a sabiendas de los detalles de su vida anterior, la tornan aún más próxima y más cotidiana:

"Por lo regular la vida de una estrella de la pantalla puede servir para otra estrella de la pantalla. Poco es lo que hay que cambiar. Siempre se trata de lo mismo. Una infancia como cualquier otra; una juventud dominada por un acendrado anhelo artístico y, desde luego, por un invariable afán de aparecer en la pantalla, una adolescencia llena de vicisitudes, de decepciones y pequeños fracasos; y, luego, como final obligado: el triunfo". ${ }^{14}$

Las estrellas establecen un estatuto que, de acuerdo con la propuesta de Quiroga, puede leerse desde tres ópticas: la primera respecto a la necesidad de que la star acompañe su brillo de buenas actuaciones; la segunda, la Belleza como entidad inherente a la existencia de la estrella -virtud suprema-, y la tercera, la dialéctica entre la figura de la estrella y el personaje que interpreta (resultado del culto a su Belleza celebrado por los espectadores). El cine como universo adopta una cantidad estimable de conceptos religiosos para expresar cosas mundanas y para darle forma a una retórica propia a través de metáforas estereotipadas: Hollywood como el firmamento; las Stars como dioses sagrados y la sala de proyección como lugar en el que la liturgia estelar estalla y nace el culto sagrado a las estrellas. En cuanto a esto último, Gilbert Simondón, en su ensayo El modo de existencia de los objetos técnicos, argumenta que la época moderna se caracteriza por la absorción en la tecnicidad de muchos aspectos de la religiosidad

\footnotetext{
${ }^{13}$ Cecil Blount de Mille, uno de los directores reseñados por Quiroga, fue quien, en 1918, lanzó a la linda muchacha picante y excitante sobre la pantalla americana buscando siempre "Belleza-juventud-sex-appeal". Más allá de que en estas estrellas hubo una reformulación estética, el modelo de la vampiresa fue trasplantado al cine americano siguiendo ciertos parámetros de la Vamp del cine europeo, encarnada por Theda Bara, primera vampiresa de aquel cine.

14 “Jean Harlow, La rubia platinada", Caras y Caretas nº 1921, Año XXXVIII, Buenos Aires, 27 de julio de 1935. (El nombre del cronista no figura.)
} 
y del arte. En términos conceptuales la tecnicidad domina la cultura de modo que la religiosidad y la estética modernas se encuentran en su procedimiento: "la tecnicidad debe ser comprendida a través de la genealogía de sus relaciones con la religiosidad y con lo estético, más allá de la técnica, la religión y el arte" (Simondón, 2008, p. 21).

En cuanto a la primera óptica, Quiroga determina que el brillo estelar ("cara cinematográfica") deberá estar acompañado de una buena actuación ("naturalidad imponderable”) la cual se aleja del gesto exagerado o mimético tan caro a las representaciones teatrales. Constantemente subraya que el factor determinante del actor de cine debe ser la expresión. Importa menos la destreza para la actuación que la expresión innata de un par de ojos, de un rostro o de un cuerpo. Así remarca el abismo existente entre los actores de teatro y los de cine. Sin embargo, observa que esta expresividad y belleza deben articularse con la marcación del director:

"La señorita Dalton no tiene suerte con sus directores. Rara vez está en papel a pesar de que su belleza total -y la muy característica de sus ojos- evitan que la imaginación se aparte un instante de su figura. Pero queremos creer que no todos los espectadores son hombres. Y aun nosotros observamos esto: que desde Rosa de Fuego y El diez de diamante, son contadísimas las cintas adaptadas al temperamento de Miss Dalton. Es voz sonada que la artista decae. ¿No decaerá mejor el tino de sus directores?” (Quiroga, 1997, p.58).

Dicho criterio lo acerca a la postura estética que, años más tarde, desarrolló André Bazin, bajo el concepto de arte de la realización lo cual acerca a Quiroga a la sensible y fina percepción que tempranamente tuvo del novedoso lenguaje de las imágenes. Como advertimos, en 1918 comienza a elaborar una escritura que, aunque muy intuitiva y experimental, interviene en algunos presupuestos que más tarde conformarán los más avezados estudios sobre cine de grandes teóricos europeos. ${ }^{15}$

En cuanto a la segunda, el narrador advierte que la belleza es inherente a la estrella, es su virtud esencial, es su lengua. La estrella es, existencialmente, bella. Para decirlo con Morin, "la belleza es una de las fuentes de la estelaridad"; "La Belleza es actriz de cine" (1957, p. 191). El encanto particular de las estrellas de cine deviene de un ritual: el de estar 45 minutos sentados frente a una pantalla, tiempo en el que los espectadores no se privan de nada ni siquiera de olvidar que entre ellos y la estrella existe una distancia imposible de franquear:

“(...) la distancia que media entre nuestras pestañas y la extremidad de las de ellas [de las estrellas]. Nada, pues, más natural que salgamos de la sala con la cabeza cálida, y el corazón, el viejo corazón de los engaños, latiendo lentamente un compás de tardía dicha" (Quiroga, 1997, p. 44);

“(...) Como la luz del día, corren por la eléctrica pantalla, tan vivas, tan del momento, que por poco que extendieran los labios o las manos, alcanzarían a tocarnos” (Quiroga, 1997, p. 310).

\footnotetext{
${ }^{15}$ Quiroga va a escribir sobre las direcciones de David Griffith, Thoman Ince y Cecil B. de Mille, y en su análisis, va a adelantarse a criterios que, más tarde, serán elaborados por teóricos del cine. Uno de los casos más significativos es la valoración que hace de los westerns de Thomas Ince, en la que con absoluto desconocimiento, coincide con Jean Mitry. (Este análisis lo tomamos del estudio preliminar de Carlos Dámaso Martínez a Horacio Quiroga. Arte y lenguaje del cine, op. cit., p.20).
} 
A través de una ilusión técnica, los espectadores no ven un personaje en la pantalla, no ven una estrella que cumple un rol artístico sino, a una mujer "realmente" deseable, miran absortos: la vida misma de la estrella en la pantalla. "¡La belleza es un equivalente afectivo de todas las demás virtudes, cuando no resulta la virtud suprema!” (Morin, 1957, p. 193).

Tercera óptica entonces, Quiroga, por momentos, no reconoce la mediación que impone un guión cinematográfico y se da el lujo de confundir a la actriz con el rol que encarna. Será ésta una confusión típica de cualquier espectador de cine. En ella reside el valor fundamental que contribuye a la transformación de la estrella en mito universal y en mercancía. Y, ciertamente, esta confusión se alimenta de la participación de las técnicas dramáticas que la favorecen. La actriz de cine no se coloca una máscara; por lo tanto, entre el gesto artístico cinematográfico y el espectador no hay distancia posible, de la que resulta "la naturalidad imponderable". Quiroga se confunde porque "la belleza arquetípica de la estrella vuelve a encontrar el hieratismo sagrado de la máscara; pero la máscara -en el cine- ha llegado a ser perfectamente inherente, se ha identificado con el rostro, se ha confundido con él” (Morin, 1957, p. 127).

Esto condiciona las decisiones de las actrices porque, al estar conscientes del lugar que ocupan ante el gran público, rechazan papeles por resultarles inmorales volviéndose, incluso, un tópico en algunas notas:

"La estrella de cine Priscilla Dean ha sido demandada por la empresa Universal con quien tenía contrato, por negarse a interpretar un papel de mujer inmoral (...). Alega la actriz que esos papeles no convienen porque el público otorga a la mujer en privado las cualidades de los personajes que interpreta" (Quiroga, 1997, p. 335).

En "La inmoralidad privada", de 1922, Quiroga no se priva de mostrar que conoce perfectamente los límites entre el actor y su personaje, vale decir, no renuncia a ese papel que también cumple como espectador típico e instala en la discusión el concepto de la sustitución:

"El actor nada tiene que ver con el personaje que interpreta. Su solidaridad con él es la misma que tienen los actores con las ideas privadas del apuntador, que les sopla su papel: comienza y concluye también en la abolición ocasional y momentánea de su personalidad, para adoptar la del ente que la sustituye" (Quiroga, 1997, p. 335).

Las estrellas participan de todos los planos: el imaginario, el simbólico, el mitológico y el sagrado aunque para intervenir en cada uno de ellos lo hacen desde la superficie de lo real y se retroalimentan de cierta vida afectiva a través de la apropiación que los espectadores hacen de su rostridad. Lo que los espectadores ignoran es que ese rostro humano muestra una suerte de 
muerte perpetua que el cine viene a salvar despojando el rostro y volviéndolo puro gesto singular. ${ }^{16}$

${ }^{16}$ La idea de rostro como muerte perpetua la tomamos del ensayo "El rostro humano" de Antonin Artaud (1947). Traducción de Martín Caparrós y Christian Ferrer en http://www.revistaartefacto.com.ar/pdf_notas/47.pdf 


\section{Bibliografía}

STAM, ROBERT; ROBERT BURGOYNE, SANDY FLITTERMAN-LEWIS. Nuevos conceptos de la teoría del cine. Buenos Aires: Paidós, 1999.

ARLT, ROBERTO. Notas sobre el cinematógrafo. Prólogo de Jorge B. Rivera. Edición de Gastón Sebastián M. Gallo. Buenos Aires: Ediciones Simurg, 1997.

BENJAMIN, WALTER. "La obra de Arte en la época de la reproductibidad técnica” en Estética y Política. Traductores Tomás Joaquín Bartoletti y Julián Fava. Prólogo Ralph Buchenhorst. Buenos Aires: Las Cuarenta, 2009, pp. 101-128.

BORGE, JASON. Avances de Hollywood. Crítica cinematográfica en Latinoamérica, 19151945. Rosario: Beatriz Viterbo Editora, 2005.

CASTORIADIS, CORNELIUS. La institución imaginaria de la sociedad. Barcelona: Tusquets, 1983.

DELEUZE, GILLES Y FÉLIX GUATTARI. Mil mesetas, Capitalismo y esquizofrenia. Valencia: Pretextos, 2006.

GUMBRECHT, HANS ULRICH. En 1926. Viviendo al borde del tiempo. Traducción de Aldo Mazzucchelli. México: Universidad Iberoamericana A.C., 2004.

KRACAUER, SIEGFRIED. La fotografía y otros ensayos. El ornamento de las masas I. Barcelona: Gedisa, 2008.

MOM, ARTURO S. "Natacha Rombova habla con el espíritu de Valentino" en revista La Nación, número 1, tomo 1, Buenos Aires: 7 de Julio de 1919.

MORIN, EDGAR. El cine o el hombre imaginario (1956). Barcelona: Paidós Comunicaciones Cine, 2001.

. Las estrellas del cine. Buenos Aires: EUDEBA, 1957.

MULVEY, LAURA. Arte después de la modernidad. Nuevos planteos en torno a la representación. Brian Wallis, ed. Madrid: Akal, 2001.

OLIVARI, NICOLÁS. El hombre de la baraja y la puñalada. Y otros escritos sobre cine. Estudio preliminar de María Gabriela Mizraje. Buenos Aires: Adriana Hidalgo editora, 2000.

QUIROGA, HORACIO. Arte y lenguaje del cine. Estudio preliminar a cargo de Carlos Dámaso Martínez, compilación de textos Gastón Gallo, con la colaboración de Denise Nagy. Buenos Aires: Editorial Losada S. A., 1997.

QUIROGA, HORACIO. Horacio Quiroga. Todos los cuentos (1993). Edición crítica. Coordinadores: Napoleón Baccino Ponce de León y Jorge Lafforgue. Madrid: Colección Archivos, Fondo de Cultura Económica, Segunda edición, mayo de 1996. 
QUIROGA, HORARIO. Lo que no puede decirse y otros textos. Recopilador y prólogo: Pablo Rocca. Montevideo: Ediciones de la Banda Oriental, 1994.

SAÍTTA, SYLVIA. El escritor en el bosque de ladrillos. Una biografía de Roberto Arlt, Buenos Aires: Sudamericana, 2000.

SIMONDON, GILBERT. El modo de existencia de los objetos técnicos. Prólogo a cargo de Pablo Rodríguez. Buenos Aires: Prometeo Libros, 2008.

SARLO, BEATRIZ. Una modernidad periférica: Buenos Aires 1920 y 1930 (1988). Buenos Aires: Grupo Editorial Norma, Tercera edición, marzo de 1999.

SPERANZA, GRACIELA. Manuel Puig. Después del fin de la literatura (2000). Buenos Aires: Grupo Editorial Norma, 2003. 